\title{
Plastic Surgery After Ablative Cancer Surgery
}

\author{
Gaston-Francois Maillard, M.D., and Laurence Garey M.D., Ph.D. \\ Avenue de la Dole 17, CH-1005, University of Lausanne, Lausanne, Switzerland
}

\begin{abstract}
Plastic and reconstructive surgery often is conceptualized either as "cosmetic" or as involving complex operations with massive flaps or time-consuming and difficult microsurgery. A number of personal cases are used to illustrate that reconstruction after cancer surgery, even reconstruction of some large tumors, can be performed with modern modifications of classic local flaps, but that sound knowledge and skill in basic surgical and plastic techniques are inescapable prerequisites.
\end{abstract}

Key words: Cancer surgery-Local flaps-Plastic surgery-Reconstructive surgery

The various classic techniques of plastic surgery can give excellent results, even in the face of large tumors. The different possibilities of plastic and reconstructive surgery are not all well known or understood. Many cases require simple autologous reconstruction without recourse to microsurgery. We attempt to illustrate some of the current possibilities based on the progress made with autologous "random" or arterial pedicle flaps.

The attitude of surgeons has evolved over recent years toward a less mutilating form of cancer surgery for two main reasons. First, the pathologic classification of tumors has improved. If there is only local involvement, surgical treatment is likely to be curative. However, if there are blood-borne or lymphatic metastases, surgery remains complementary to a generalized oncologic management via chemo- or radiotherapy. Second, surgeons have long underestimated the psychological impact of mutilation [11].

Correspondence to Gaston-Francois Maillard, Avenue de la Dole 17, CH-1005, Lausanne, Switzerland; email:1.garey@, freesurf.ch
We have slowly realized that a number of poorly informed patients might prefer the risk of the tumor spreading rather than face irreparable mutilation.

Especially since the 1980s, techniques for autologous reconstruction have been published, especially in breast surgery $[3,4,15,16]$. Autologous or prosthetic reconstruction of the breast has provided great practical help in rehabilitation after ablational surgery above and beyond the mass of theoretical and statistical data. The aim of plastic and reconstructive surgery is to reestablish function as fully as possible on the one hand, and to restore the anatomic appearance sacrificed in the treatment of the tumor on the other.

In 1975 , plastic reconstructive and cosmetic surgery was born officially as a speciality in Switzerland. Previously, it had been a subspeciality of general and ear, nose, and throat surgery. To adapt to international standards, it became evident that it was necessary to require a solid basis of general surgery before a surgeon could become a specialist. The experience gained by the French, and especially the British, in the World Wars was soon incorporated [7]. Sir Harold Gillies and his colleagues were the real founders of modern plastic surgery, amassing an extraordinary experience from the war wounded, particularly the pilots of the Royal Air Force.

Knowledge spread rapidly on an international scale thanks to conferences and the creation of university chairs of plastic surgery. Three examples of "spin-offs" may be cited:

Craniofacial surgery, created and described by Paul Tessier [19], involves novel planes of dissection and gives an "orthomorphic" dimension to facial surgery. Microsurgery, initially of nerves and then of microvessels, has permitted the reimplantation of limbs. The first reimplantation of an upper limb in Switzerland was achieved at Lausanne in 1973 [14]. At this 

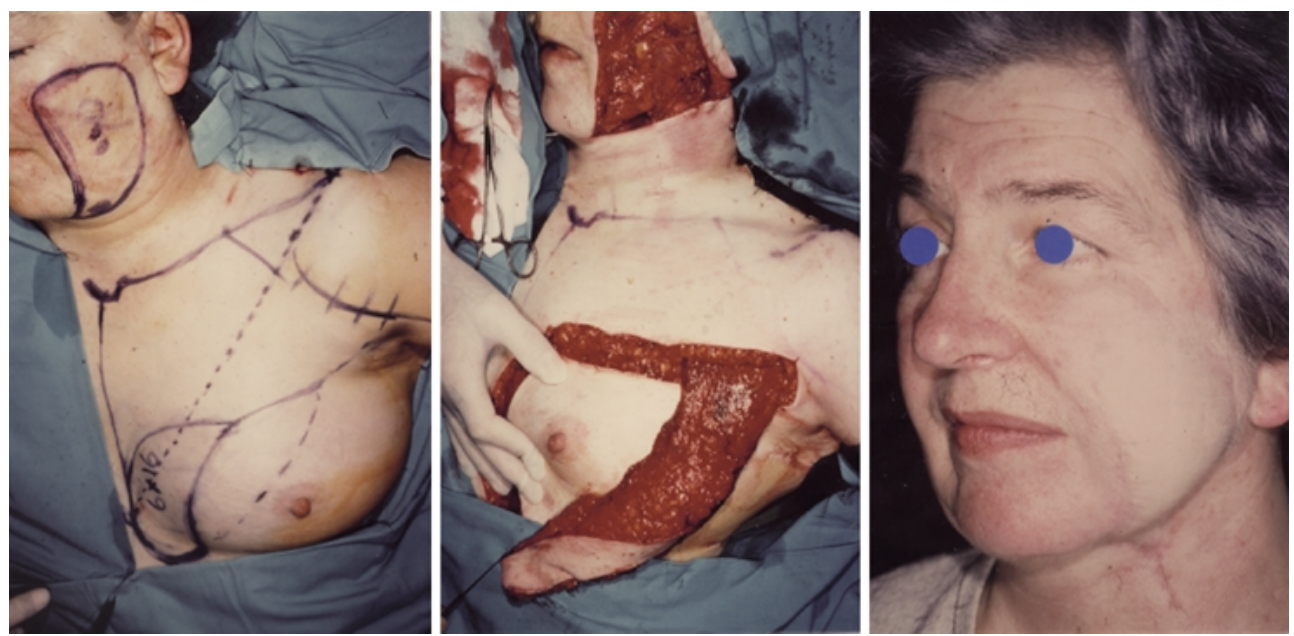

Fig. 1. Relapsing melanoma of the neck with satellite nodules and submental and submandibular adenopathy. Wide monobloc excision of the whole cheek, including submental and submandibular nodes. Immediate reconstruction using a musculocutaneous pectoralis major flap carrying a $6 \times 16-\mathrm{cm}$ skin-fat flap. The advantage of this approach is that it is a local vascularized pedicle flap, but not from the region threatened by possible lymphatic metastases. It also avoids difficult, timeconsuming microsurgery.
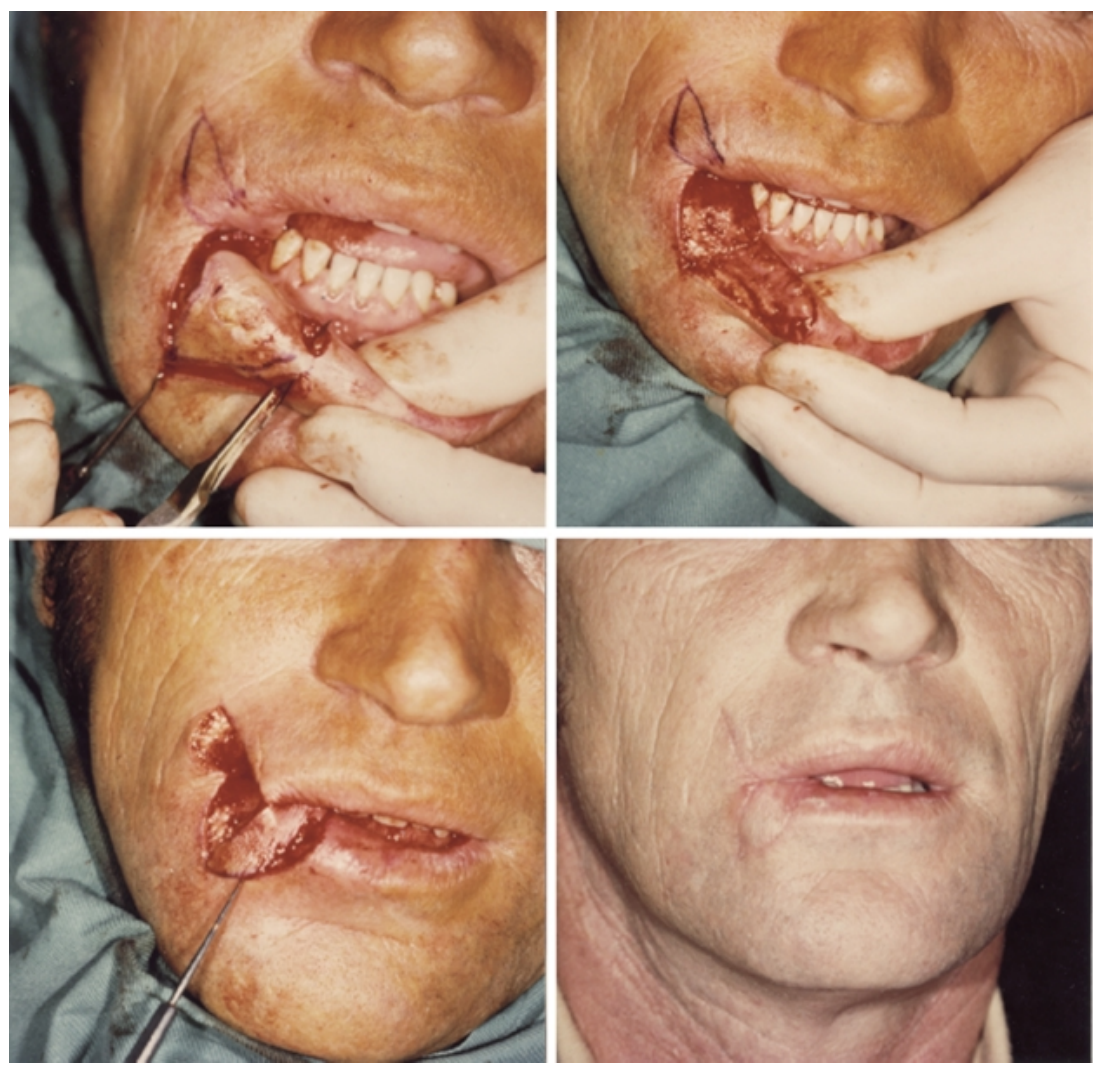

Fig. 2. Spinocellular epithelioma infiltrating the lateral third of the right lower lip. Reconstruction by a pedicled Abbé-Eslander flap [1] based on the inferior labial artery. The advantages are that it is an immediate autologous reconstruction with an acceptable scar. The geometric rule that a loss of substance can be replaced by a flap of half its width applies. Here, a third is replaced by a sixth. writing, the patient still is in excellent health, with at least $80 \%$ function of the upper limb. Microsurgery also is the basis of free flaps, that is, the free transplantation of a block of tissue vascularized by an arterial axis and its venous return, then anastomosed with microsutures. After a certain period of excessive enthusiasm for these free flaps, their indications became more precisely defined. Indeed, the knowledge and skills acquired from their use are now applied to a large extent for "axial" flaps, that is, pedicle flaps on an arterial axis such as the latissimus dorsi flap [4], the transverse rectus abdominis myo- 

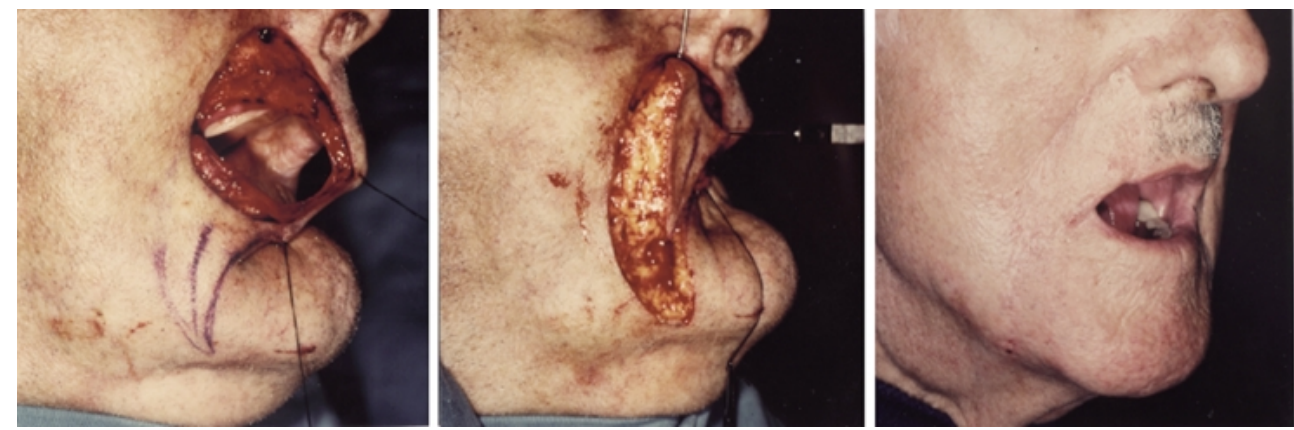

Fig. 3. Large infiltrating basal cell carcinoma (rodent ulcer) perforating the upper lip into the mouth. Monobloc resection including buccal mucosa. Autologous repair using a pedicled subcutaneous kite flap based on the facial artery to reconstruct the superficial and muscular planes, with the mucosa repaired by internal mobilization. The advantage here is that this is a wholly functional autologous reconstruction that can be performed with the patient under local anesthesia with an immediate result.
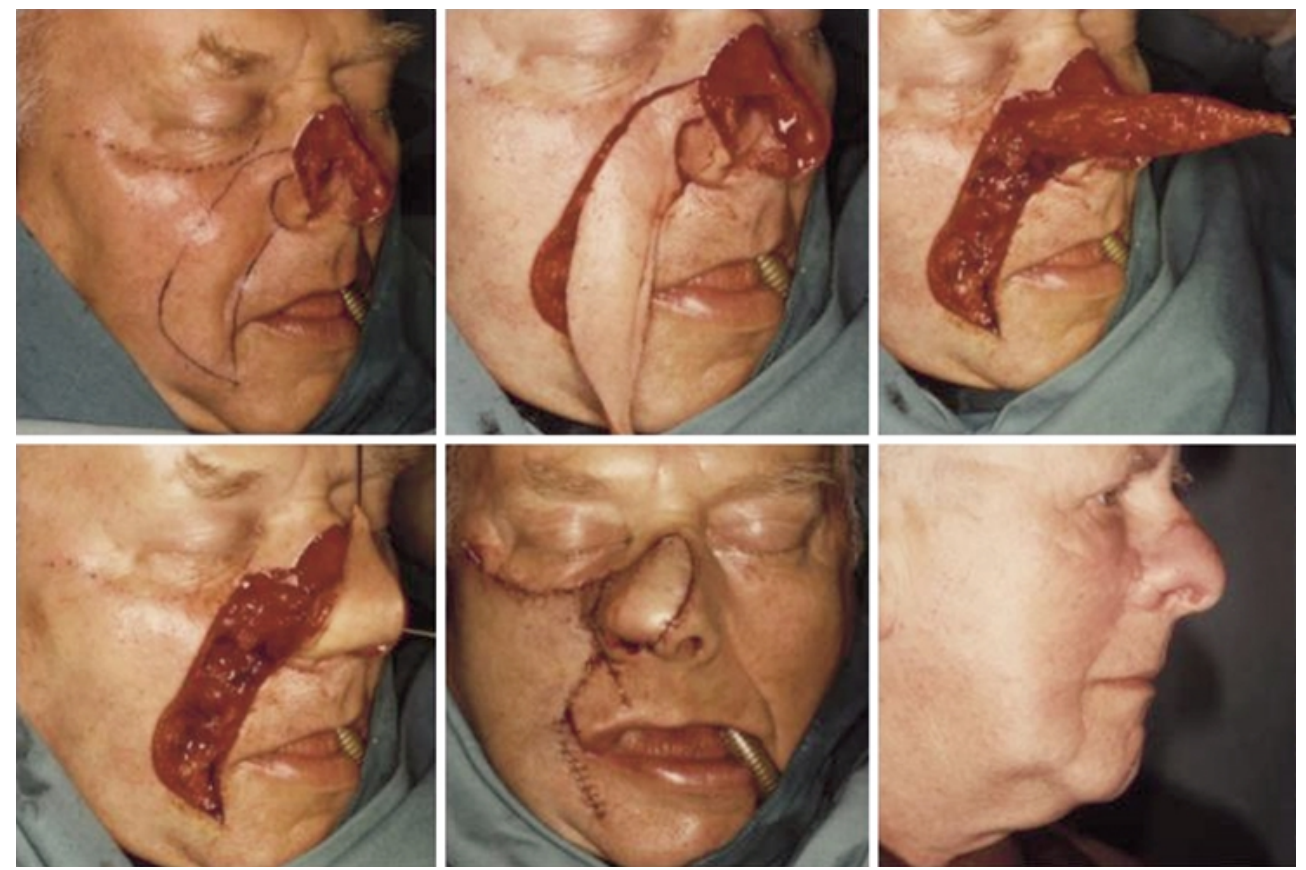

Fig. 4. Amputation of half the nose for a carcinoma infiltrating the whole thickness of the nostrils. Reconstruction by a nasolabial Pers flap [10] rolled on itself. This is a subcutaneous flap on the facial artery. The rolling permits reconstruction of both the superficial and deep surfaces. The tissue loss is closed by a cheek advancement, with the scar hidden in the nasozygomatic and, especially, the nasolabial folds. The advantages are an almost invisible scar from the flap donor area, as well as an autologous reconstruction the same color and texture as the nasal skin.

cutaneous (TRAM) flap $[8,9,13]$, or the inferior transverse abdominal flap [5].

Biomaterials resulting from the development of various synthetic substances have changed the materials used in plastic surgery, especially for sutures and implants. Over the years, we abandoned catgut sutures, replacing them with derivatives of polylactic acid absorbable by slow hydrolysis rather than by macrophagic phagocytosis [6]. The much improved solidity of these sutures has above all enabled us to use thinner sutures without sacrificing mechanical
resistance.Currently, nets, especially polyester or polypropylene meshes, are available to reinforce, for example, herniation through the abdominal wall $[2,21]$.

Silicone prostheses can be used as space fillers to improve shape. Two examples are testicular prostheses and chin prostheses for retrognathia. A third example, the breast implant, is the prostheses best known because a pseudoscientific judicial imbroglio some have called "silicone-gate" was very widely publicized in the media and manipulated by certain 

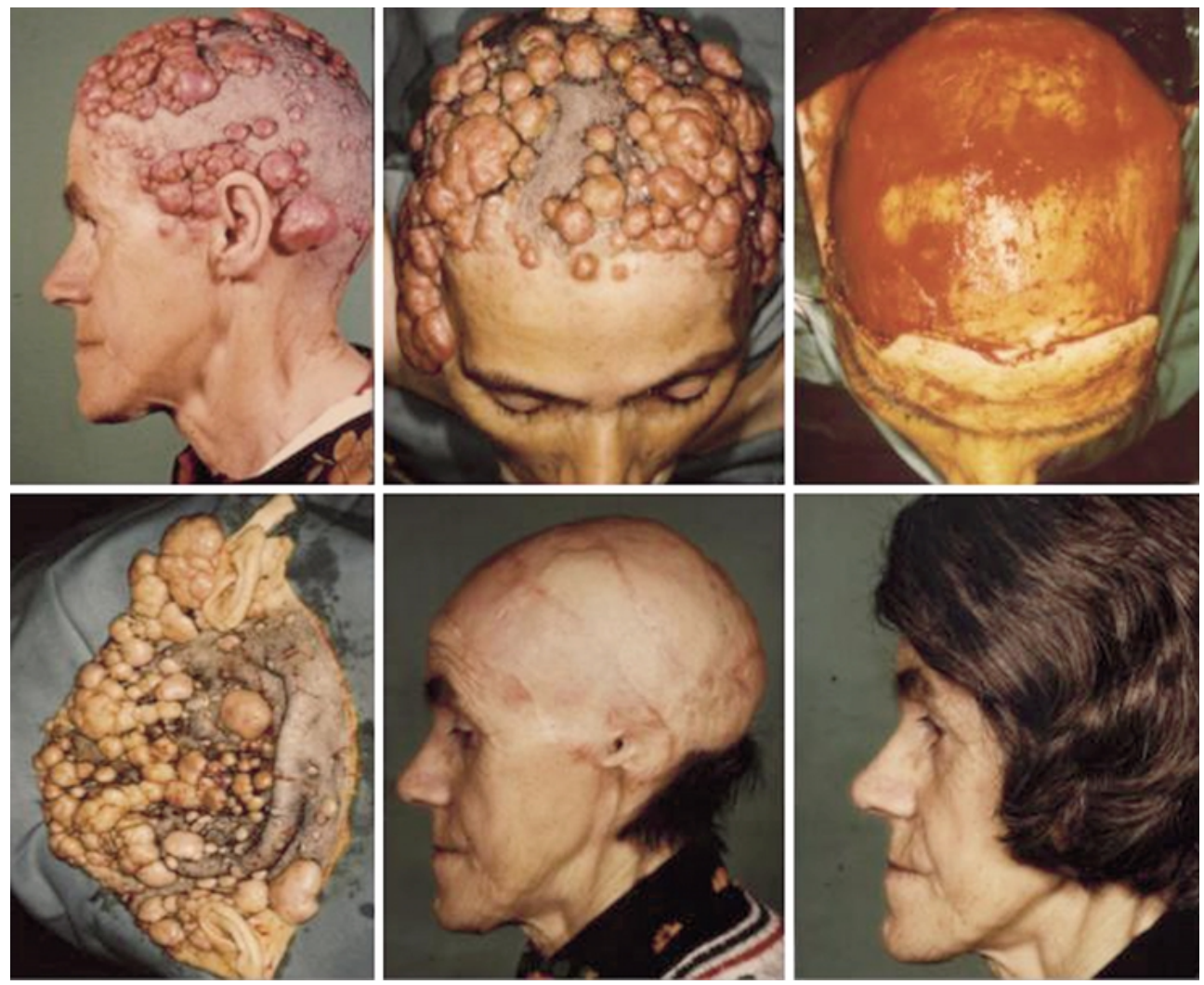

Fig. 5. Massive cylindroma of the scalp (turban tumor) also infiltrating the helix of both auricles. A total scalping with careful preservation of the pericranium. Repair by partial-thickness skin graft and the wearing of a wig. The advantage is that this is radical surgery with the maximum chance of avoiding relapse of this frequently recurring tumor. The technique is relatively simple, but nevertheless requires technical skill for the graft to take in the head region.
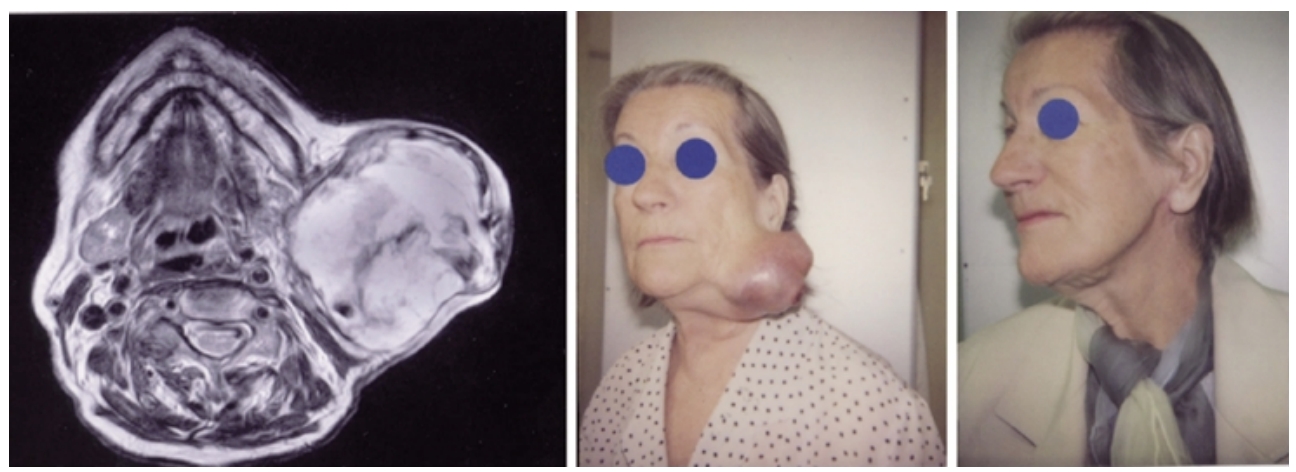

Fig. 6. Enormous mixed tumor of the parotid that had been neglected for many years. When the patient finally decided to undergo treatment, the tumor presented signs of necrosis and hemorrhage. After anatomic localization by magnetic resonance imaging, a radical parotidectomy was performed that included the skin, local nodes, and submandibular nodes. A wide cervicofacial advancement-rotation flap permitted an immediate satisfactory reconstruction. The zygomatic and buccal branches of the facial nerve were preserved. This tumor was almost inoperable, but its ablation was made possible by the Klein tumescent technique [12]. This operation was performed in collaboration with Dr. R de Goumoens.

American lawyers. Silicone, introduced 60 years ago, has been applied in medicine for 50 years. Mammary implants have been in use for 40 years. These facts together with the introduction of European Standard EN 12180 and the availability to the public and the medical profession of modern technical specifications and medicolegal guidelines (e.g., the $\mathrm{ABC}$ of mammary implants published by the Swiss Federal Office of Public Health in 2001 [17]) have made the situation quite clear and positive. 

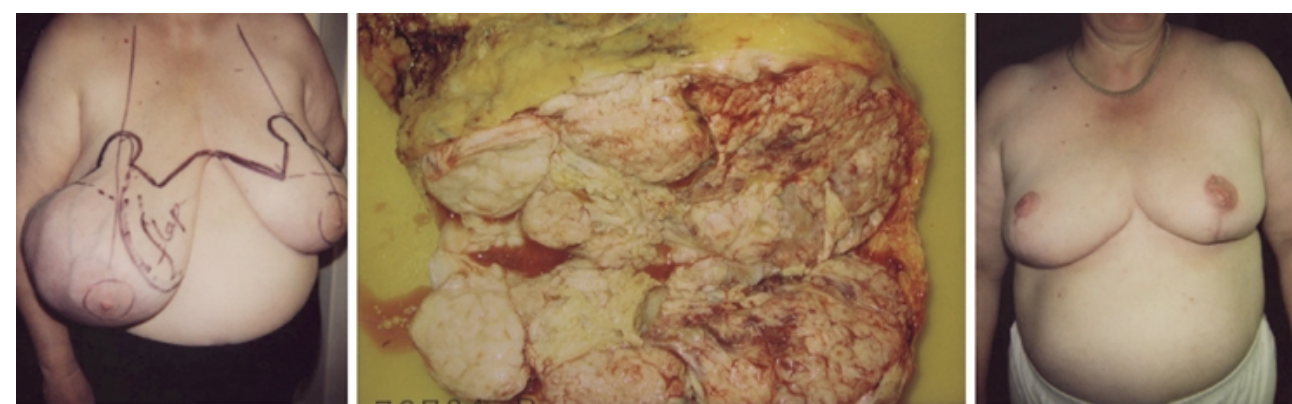

Fig. 7. Subtotal right mastectomy for a tumor weighing $3.8 \mathrm{~kg}$. Immediate reconstruction by a large local skin-fat flap. The nipple-areola complex was reconstructed by a composite graft. The contralateral breast was remodeled using Thorek's technique [20] to achieve symmetry. Blood loss was minimal thanks to the Klein tumescent technique. The operation was in collaboration with Dr. Philipe Sauthier.
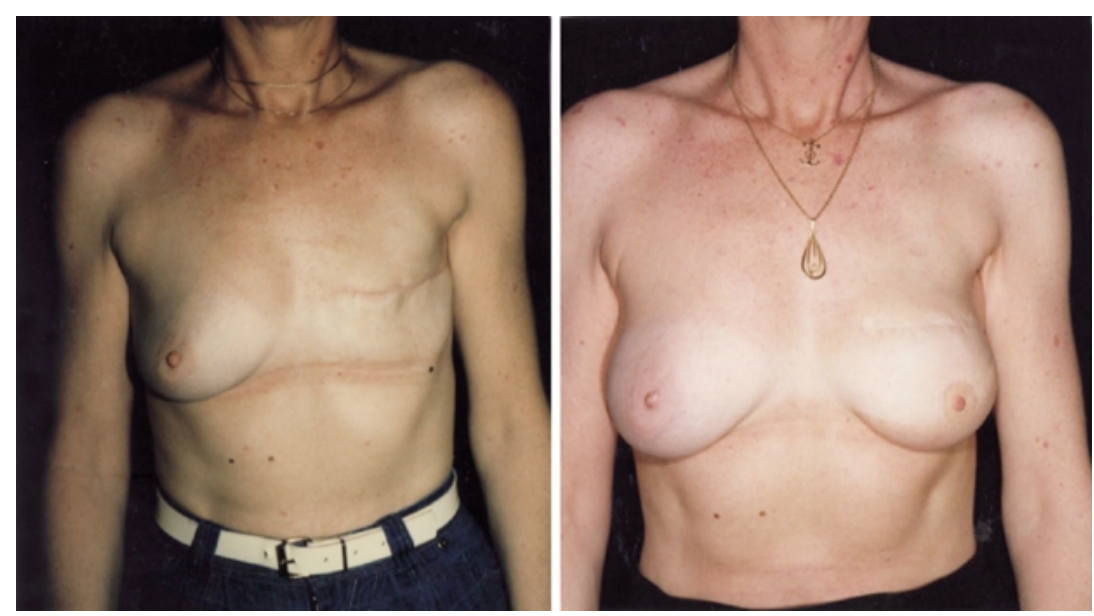

Fig. 8. A 45-year-old woman with Patey modified radical mastectomy [18], before and after reconstruction with an autologous latissimus dorsi flap, and as a second stage, replacement of the nipple-areola complex by local autoplasty with a vulva graft for the areola.

Thus, plastic and reconstructive surgery is not limited to a few well-known cosmetic operations such as blepharoplasty, rhinoplasty, face-lifts, breast surgery, abdominoplasty, and liposuction. Its field of application is much wider. Furthermore, it is not a minor surgical speciality involving merely surgery of the skin. It is the surgery of all systems, with the possible exception of the internal viscera. With modern modifications of classic techniques, it is now possible to perform excellent reparative surgery after tumor resection without recourse to major, difficult, and risky surgery. However, wide knowledge and extensive surgical experience are necessary for the practice of this speciality. Basic skills in ear, nose, and throat surgery as well as maxillofacial and orbital surgery are indispensable. After 25 years of personal experience in this domain, I illustrate the possibilities now available by the cases presented in Figs. 1 to 8 .

\section{References}

1. Baker SR: Reconstruction of facial defects In: Cummings CW, Fredrickson JM, Marker LA, Krause CJ,
Richardson MA, Schuller DE (eds) Otolaryngology: Head and neck surgery. Vol. 1, 3rd ed. Mosby, St Louis, pp 544-548, 1998

2. Bernaschek W: Polyester nets in the operative management of hernias of the anterior abdominal wall (in German). Münch Med Wochenschr 104:2302-2303, 1962

3. Bohmert $\mathrm{H}$ : Breast cancer and breast reconstruction. Georg Thieme Verlag, Stuttgart, 1982

4. Bostwick J, Scheflan M: The latissimus dorsi musculocutaneous flap: A one-stage breast reconstruction. Clin Plast Surg 7:71-78, 1980

5. Classe JM, Gamier JM, Drianno JC, Guillard Y: Breast reconstruction with inferior transverse abdominal flap after mastectomy for cancer (in French). J Gynécol Obstét Biol Reprod (Paris) 22:827-832, 1993

6. Cutright DE, Hunsuck EE: Tissue reaction to the biodegradable polylactic acid suture. Oral Surg Oral Med Oral Pathol 31:134-139, 1971

7. Gilles H, Millard DR: The principles and art of plastic surgery Little, Brown, Boston, 1957

8. Hartrampf CR: The transverse abdominal island flap for breast reconstruction: A 7 year experience. Clin Plas Surg 15:703-716, 1988

9. Hartrampf CR, Scheflan M, Black PW: Breast reconstruction with a transverse abdominal island flap. Plast Reconstr Surg 69:216-225, 1982 
10. Hubault-Marcade P, Darsonval V, Simon P, Duly T, Delahaye JF: The Pers flap in the reconstruction of distal nasal defects (in French). Ann Chir Plast Esthet 36:228-234, 1991

11. Jamison KR, Wellisch DK, Pasnau RO: Psychological aspects of mastectomy: Women's perspective. Am J Psychiat 135:432-436, 1978

12. Klein JA: The tumescent technique for liposuction surgery. Am J Cosmet Surg 4:263-267, 1987

13. Maillard GF: Breast reconstruction: I TRAM flap II: Latissimus dorsi flap: A surgical technique in detail. Eur Plast Surg Rev 5:22-25, 2000

14. Maillard GF, Livio JJ, Chappuis G: Resultat de deux réimplantations de members supérieurs. Méd et $\mathrm{Hyg}$ 34:370, 1976

15. Maillard GF, Montandon D, Goin JL: Plast Reconstr Surg Masson, Paris, 1983

16. McGraw JB, Vasconez LO: Musculocutaneous flaps: Principles. Clin Plast Surg 7:9-13, 1980
17. Office Fédéral de la Santé Publique: L'ABC des implants mammaires, 2001. Retrieved at http://www.bag. admin.ch/md/f/abc-text.htm\#Anfang

18. Staunton MD, Melville DM, Monterrosa A, Thomas JM: A 25-year prospective study of modified radical mastectomy (Patey) in 193 patients. J Roy Soc Med 86:381-384, 1993

19. Tessier P: Ostéotomies totales de la face: Syndrome de Crouzon. Syndrome d'Apert. Oxycéphalies. Scaphocéphalies. Turricéphalies. Ann Chir Plast Esthet 12:273-286, 1967

20. Thorek M: Plastic surgery of the breast and abdominal wall. Springfield, Charles C Thomas, 1942

21. Zienowicz RJ, May JW: Hernia prevention and aesthetic contouring of the abdomen following TRAM flap breast reconstruction by the use of polypropylene mesh. Plast Reconstr Surg 96:13461350, 1995 